\title{
PEMANFAATAN APLIKASI OWNCLOUD PADA SISTEM KEAMANAN CLOUD COMPUTING
}

\author{
Edy Rakhmat ${ }^{1}$, Saleh Dwiyatno ${ }^{2}$, Sulistiyon $^{3}$, Agus Irawan ${ }^{4}$, Ferli Setiawan ${ }^{5}$ \\ ${ }^{1}$ Universitas Banten Jaya \\ Jl. Ciwaru Raya II No. 73 Warung Pojok Kota Serang Banten \\ 2,3,4,5 Universitas Serang Raya \\ Jl. Raya Serang - Cilegon Km. 5 Taman Drangong, Serang Banten \\ E-mail: edyrakhmat@ unbaja.ac.id ${ }^{1}$, salehdwiyatno@ gmail.com $^{2}$, sulistiyonoputro@gmail.com³ \\ irawanagus.2015@gmail.com ${ }^{4}$, ferlisetiawanxii@gmail.com ${ }^{5}$
}

\begin{abstract}
Private cloud is a type of private storage or only provides limited services to an organization or an agency. OwnCloud is a company whose project is OwnCloud project. The company's slogan is "Your Cloud, Your Data, Your Way". OwnCloud is one of the free file sharing software and has provided free security and has an easy or user-friendly user interface so it is easy to use. Owncloud has several features such as creating groups, being able to easily control users and having several other features that are a solution for a cloud-based storage at the Banten Province Public Works and Spatial Planning Office UPTD Serang - Cilegon roads and bridges which do not have integrated storage and still rely on storage such as hard drives, Google Cloud and available storage on the computer or PC in the office which makes it easy to lose and not integrated, therefore a solution using owncoud is made to reduce the existing storage on the computer or PC in the office This is so that all files are stored neatly and by adding a security so that every existing user cannot access data on other users, thus the data can be maintained and cannot be seen by other irresponsible people so that it is easier to operate. its n. By using ownloud which has several features, it makes owncloud more practical.
\end{abstract}

Keywords: Access Management, Owncloud, Private cloud

\section{PENDAHULUAN}

Penggunaan teknologi komputasi semakin meningkat seiring dengan perkembangan zaman yang semakin maju (Dhika et al., 2019). Beriringan dengan perkembangan zaman, teknologi komputasi dapat menciptakan kemudahan dan kenyamanan yang luar biasa dalam mendukung pekerjaan sehari-hari yang tadinya dianggap tidak mungkin untuk dikerjakan dalam waktu singkat, hal ini dapat terjadi karena adanya kemajuan dalam teknologi jaringan khususnya internet (Suryati et al., 2019) (Mutia, 2016) (Aziz et al., 2018). Keterbatasan dalam penyimpanan data sering dijumpai ketika kita akan menyimpan file-file yang akan dipindahkan ke database internet seperti yang biasa dilakukan saat ini dengan melakukan penyimpanan data pada email, google drive, ataupun dropbox. Cara seperti ini 
sering disarankan untuk menanggulangi kekhawatiran kita terhadap kehilangan data, dengan melakukan hal ini kita menjadi tidak khawatir akan kehilangan data, karena telah memiliki back-up data yang tersimpan di email, google drive, dan dropbox (Suryati et al., 2019) (Zahara et al., 2019).

Dinas Pekerjaaan umum pada umumnya dan setiap instansi pemerintahan sudah memiliki sistem pusat yang di kelola oleh negara yang berfungsi untuk penyimpanan data seperti bidang tanah, proyek infrastruktur dan lain sebagainya. Pada Dinas pekerjaan Umum Kota Serang khususnya belum memiliki local cloud yang terintegrasi langsung ke setiap divisi yang ada sehingga beberapa karyawan pada dinas tersebut masih menggunakan penyimpanan pada komputer masing masing seperti data survei tanah, pengukuran tempat dan lain sebagainya yang tidak terpadu sehingga mudah terpisah ataupun hilang.

Dengan masalah yang ada pada kantor dinas tersebut, dibutuhkan sebuah solusi dengan menerapkan suatu metode private cloud berbasis Cloud Computing sehingga memberikan beban yang sama di setiap komputer yang ada untuk menjadikan suatu penyimpanan secara virtual (Cloud) dengan menggunakan fasilitas yang ada di dinas tersebut dan memudahkan perpindahan file menjadi jauh lebih cepat dan efisien karena memiliki sistem terpusat yang ramah untuk di gunakan.

Cloud storage merupakan salah satu solusi untuk memberikan layanan penyimpanan data secara terpusat untuk menambah kapasitas penyimpanan dan akses penggunaan data terhadap pengguna yang berhak mengaksesnya (Muqorobin et al., 2019) (B et al., 2017). Karena cloud storage dapat meingkatkan fleksibilitas dan kapabilitas dari proses yang dilakukan oleh computer secara dinamis tanpa perlu mengeluarkan investasi yang besar guna membangun infrastruktur (Nugraha, 2016). Keamanan, ketersediaan, dan kemudahan perawatan infrastruktur jaringan lebih terjamin karena sistem yang dibangun akan memanfaatkan jaringan komputer yang sudah tersedia. Dalam industry TI cloud storage merupakan sebuah solusi dan pelayanan, baik itu untuk meningkatkan kehandalan, mengurangi biaya komputasi, sehingga memberikan peluang yang besar dalam dunia industry (Rumetna \& Sembiring, 2017). 
Teknologi cloud computing merupakan teknologi terbaru dari sebuah perkembangan jaman dunia teknologi informasi (IT). Peman-faatan teknologi ini akan berpengaruh signifikan dalam dunia industri terutama dalam hal penghematan biaya oprasional. Kemudahan dan efisiensi teknologi ini membuat para pemilik perusahaan mulai meninggalkan teknologi tradisional yaitu client server yang dianggap kurang efisien (Lumena \& Nainggolan, 2016). Dengam membangun sistem Cloud Computing diharapkan dinas terkait dapat mampu mengelola data lebih efisien lagi dengan mengurangi penyimpanan yang ada pada setiap komputer yang ada dapat mampu menambah kinerja setiap PC yang ada, dan dengan adanya Cloud Computing.

\section{METODE PENELITIAN}

Metodologi penelitian adalah proses atau cara ilmiah untuk mendapatkan data yang akan digunakan untuk keperluan penelitian. Diagram alur penelitian disajikan pada gambar 1.

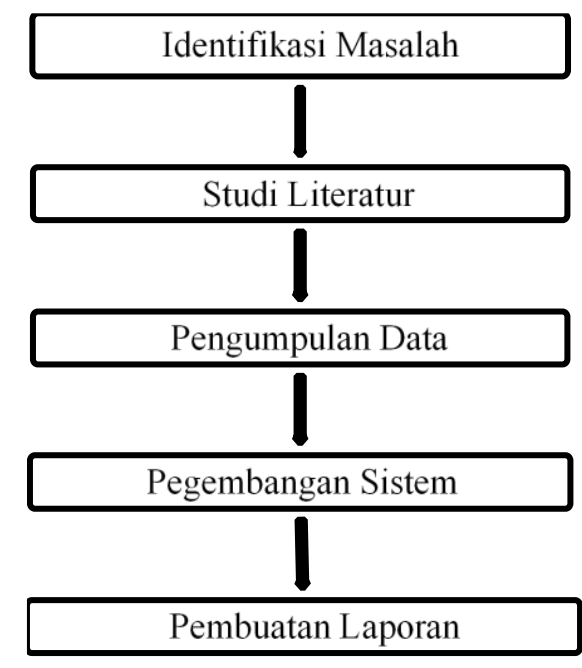

Gambar 1 Diagram Alur Penelitian

Tahap pengumpulan data yang digunakan dalam penelitian ini adalah sebagai berikut:

1. Studi Literatur. Pengumpulan data dengan studi literatur, jurnal, e-book, informasi dari internet maupun sumber-sumber lainnya yang dapat membantu dalam mengatasi permasalahan yang sedang dihadapi. 
2. Interview. Dalam metode ini penulis mengajukan wawancara atau tanya jawab kepada pihak-pihak yang terkait, serta pihak lainnya yang memiliki kontribusi positif guna mendapatkan data-data yang diperlukan.

3. Observasi. Teknik pengumpulan data dengan mengadakan penelitian dan peninjauan langsung terhadap permasalahan yang diambil.

\section{HASIL DAN PEMBAHASAN}

Pada penelitian ini dibangun aplikasi penyimpanan cloud storage dengan cara membangun sistem Cloud Computing berbasis private cloud. Sistem Cloud Computing yang di bangun dengan memanfaatkan perangkat komputer yang dimiliki oleh dinas pekerjaan umum. Perancangan di mulai dengan admin login ke aplikasi kemudian melakukan pembuatan akun user dan pemberian hak akses yang berbeda pada masing-masing user akun yang dibuat. Kemudian masing-masing akun user yang telah dibuat dapat login ke sistem dan memiliki hak akses terhadap storage yang berbeda sehingga masing-masing user tidak dapat akses ke storage yang bukan haknya. Proses perancangan dalam penelitian ini disajikan pada gambar 2.

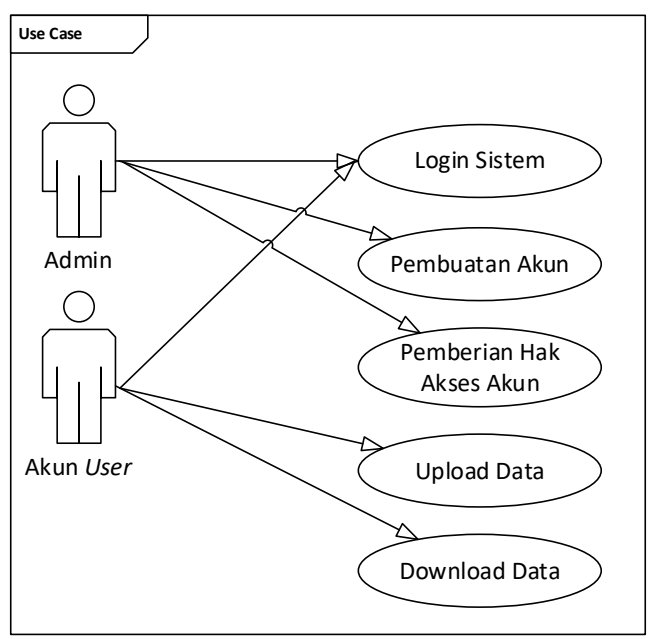

a. Use case

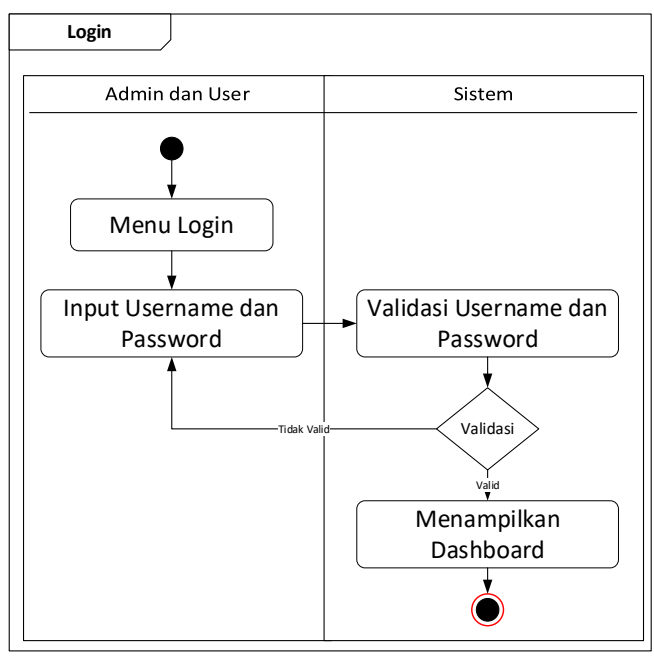

b. Activity Login 


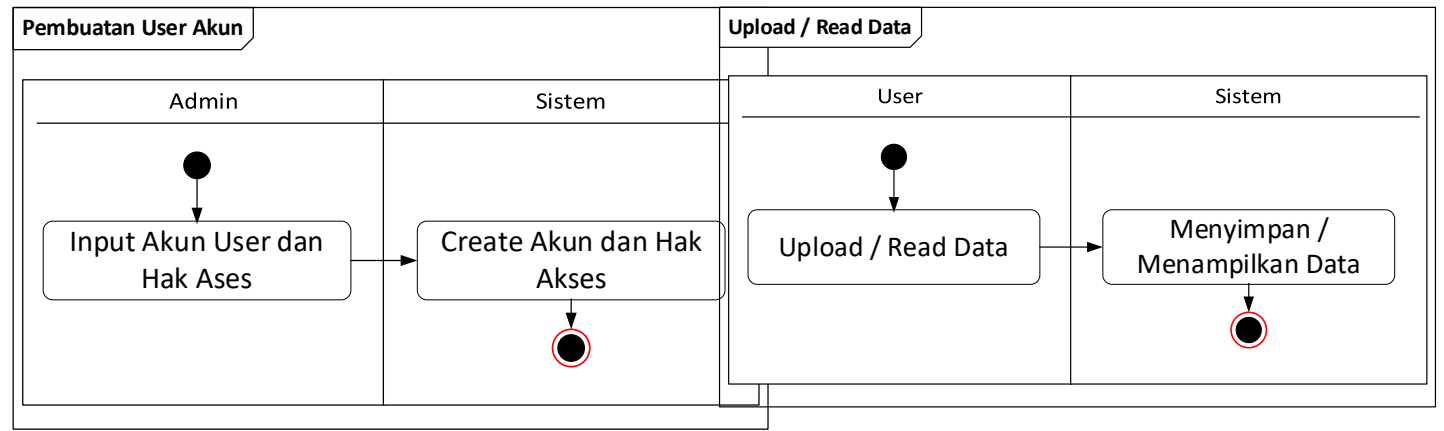

c. Activity Pembuatan User Akun d. Activity Upload / Read Data

Gambar 2. Proses perancangan sistem aplikasi owncloud

Setelah melakukan perancangan dan melalui tahap pengujian sebuah sistem penyimpanan terpadu yang berbasis private cloud yang di bangun, maka mampu mengurangi penggunaan penyimpanan yang masih membutuhkan perangkat tambahan seperti harddisk, flashdisk dan penyimpanan yang membebankan penyimpanan internal memory yang ada. Dengan demikian mampu menambah kapasitas penyimpanan tanpa harus adanya hardware tambahan. Hasil pembuatan akun user disajikan pada gambar 3 .

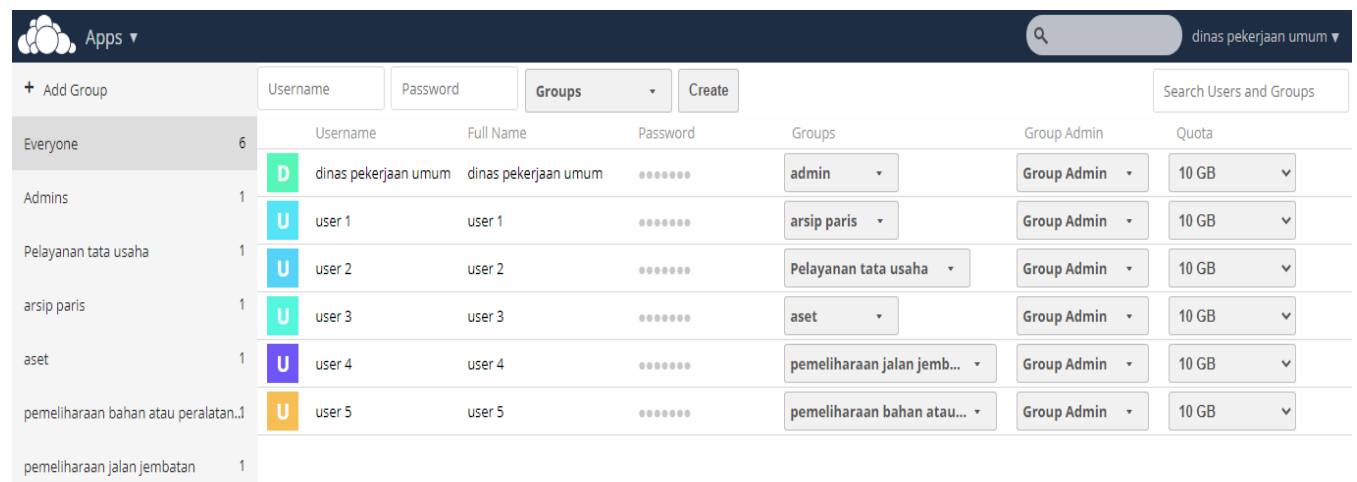

Gambar 3 Tampilan hasil pembuatan akun user

Hasil implementasi perancangan sistem aplikasi owncloud pada sistem keamanan cloud computing pada Dinas Pekerjaan Umum tersaji pada gambar 4.
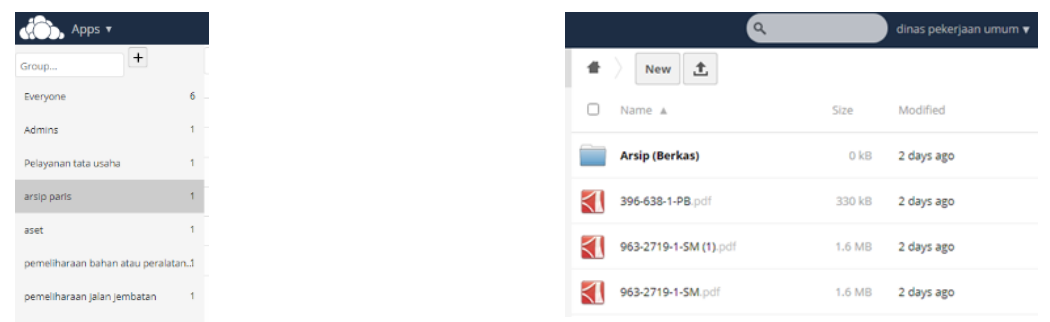
a. Hasil pengujian pembuatan Group

b. Hasil Upload berkas

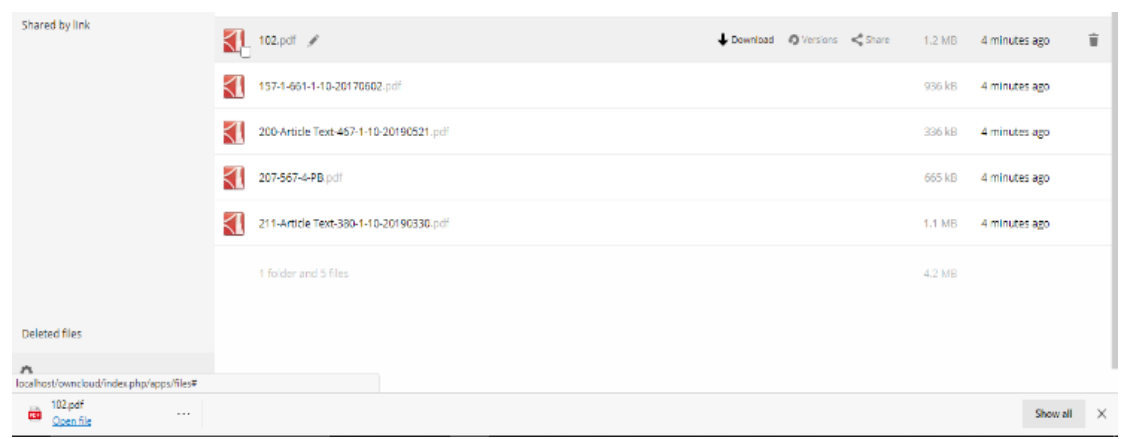

c. hasil download berkas
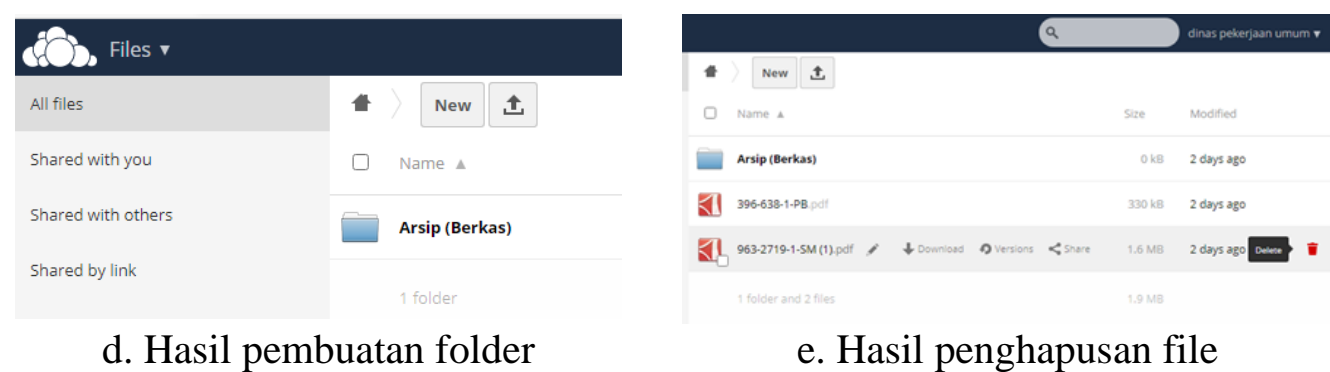

d. Hasil pembuatan folder

e. Hasil penghapusan file

Gambar 4. Hasil implementasi perancangan sistem aplikasi owncloud

Akun yang dibuat pada implementasi perancangan sistem aplikasi owncloud pada sistem keamanan cloud computing pada Dinas Pekerjaan Umum tersaji pada gambar 5.

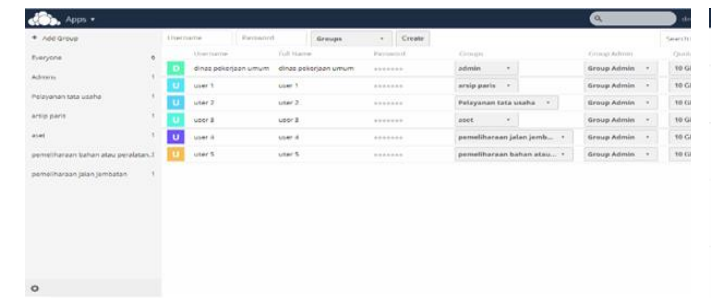

a. Akun Admin

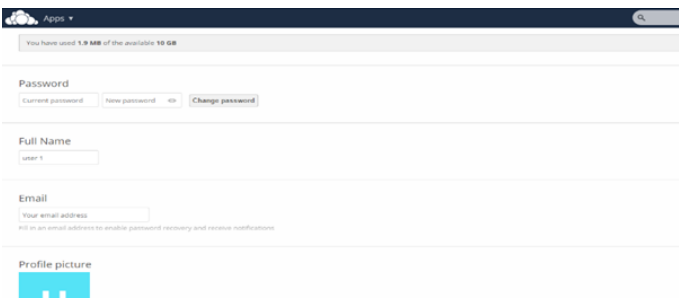

b. Akun User Sub bidang Aset
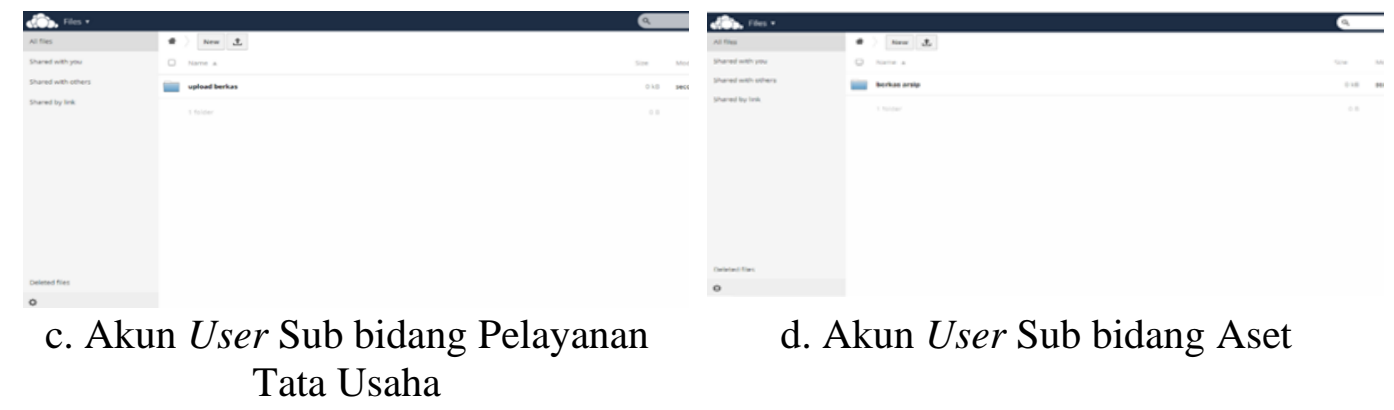

d. Akun User Sub bidang Aset 

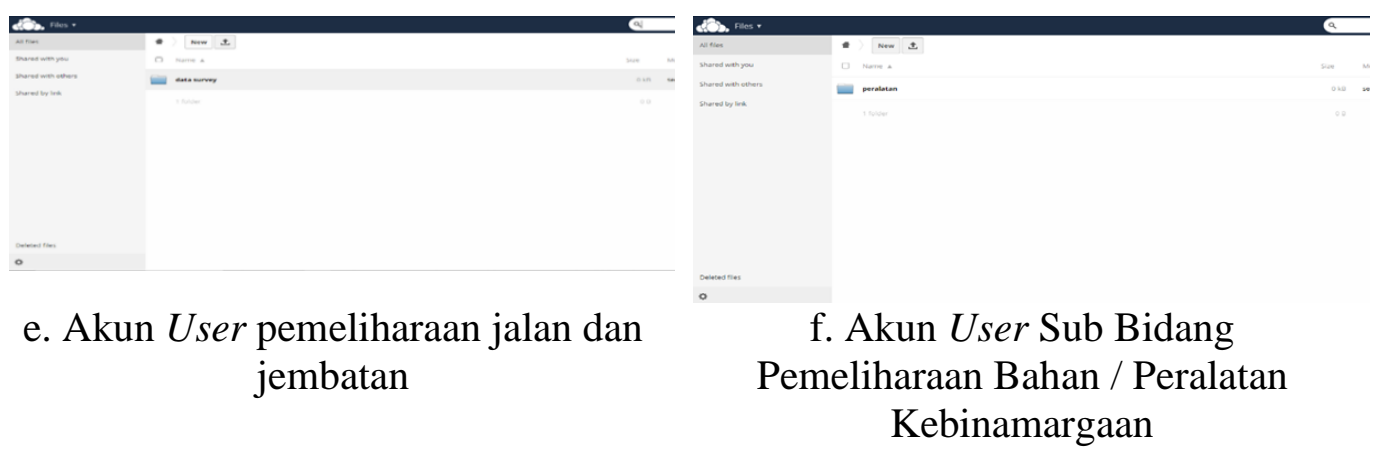

Gambar 5. Akun hasil implementasi perancangan sistem aplikasi owncloud

Setelah melakukan perancangan dan membangun sistem owncload dengan Pemanfaatan aplikasi owncloud pada sistem keamanan cloud computing. Maka didapatkan jika setiap user yang ada tidak dapat mengakses sub bidang yang ada dan tidak dapat merubah data yang di miliki sub bidang lain sehingga keamanan data menjadi lebih terjamin selain itu admin yang bertugas sebagai pengontrolan setiap akun hanya bisa melakukan penambahan akun atau melakukan pengontrolan akun yang ada tidak bisa merubah data yang di upload oleh user pada masingmasing bidang.

\section{KESIMPULAN}

Kesimpulan adalah sebuah pencapaian dari rumusan masalah yang telah dirumuskan dan menjawab dari tujuan penelitian. Bedasarkan penelitian yang telah dilakukan di Kantor Pekerjaaan Umum Kota Serang, penulis menyimpulkan:

1. Dengan dibuatnya local cloud menggunakan owncloud dengan database menggunakan PhpMyAdmin, dan pada owncloud melakukan penyetingan dengan cara membuat group untuk membagi hak user pada setiap bagian sehingga setiap user tidak dapat merubah data atau mengupload data yang bukan pada bagiannya.

2. Dengan dibuatnya local cloud menggunakan owncloud yang dapat beroperasi dengan sangat ringan dengan memanfaatkan sumber daya komputer yang ada. Hal ini sudah dilakukan pengujian fitur yang berjalan menggunakan metode black box testing dengan hasil fitur berjalan dengan lancar. 


\section{DAFTAR PUSTAKA}

Aziz, M., Fuad, A., \& Jamil, M. (2018). Implementasi Cloud Computing Sebagai Infrastruktur Layanan Mail Server Pada Universitas Khairun. JIKO (Jurnal Informatika Dan Komputer), $\quad$ 1(1), 43-50. https://doi.org/10.33387/jiko.v1i1.1170

B, R., K, L., M, I., \& H, P. S. (2017). Distributed Scheme to Authenticate Data Storage Security in Cloud Computing. International Journal of Computer Science and Information Technology, 9(6), 59-66. https://doi.org/10.5121/ijcsit.2017.9606

Dhika, H., Akhirina, T., Mustari, D., \& Destiawati, F. (2019). Pemanfaatan Teknologi Cloud Computing sebagai Media Penyimpanan Data. Jurnal PkM $\begin{array}{llll}\text { Pengabdian Kepada } & \text { Masyarakat, } & 221 .\end{array}$ https://doi.org/10.30998/jurnalpkm.v2i03.3144

Lumena, D., \& Nainggolan, E. R. (2016). Analisa Dan Perancangan Jaringan Private Cloud Computing Berbasis Web Eyeos. Jurnal Techno Nusa Mandiri Vol. XIII, No. 1 Maret 2016, XIII(1), 1-8.

Muqorobin, M., Hisyam, Z., Mashuri, M., Hanafi, H., \& Setiyantara, Y. (2019). Implementasi Network Intrusion Detection System (NIDS) Dalam Sistem Keamanan Open Cloud Computing. Majalah Ilmiah Bahari Jogja, 17(2), 1-9. https://doi.org/10.33489/mibj.v17i2.205

Mutia, I. (2016). Pemanfaatan Komputasi Awan (Cloud Computing) Bagi Pembelajaran Mahasiswa Perguruan Tinggi. STRING (Satuan Tulisan Riset Dan Inovasi Teknologi), 1(1), 1-9. https://doi.org/10.30998/string.v1i1.963

Nugraha, B. (2016). Analisis Teknik-Teknik Keamanan Pada Future Cloud Computing vs Current Cloud Computing: Survey Paper. Jurnal Nasional Teknologi Dan Sistem Informasi, 2(2), 35-42. https://doi.org/10.25077/teknosi.v2i2.2016.35-42

Rumetna, M. S., \& Sembiring, I. (2017). Pemanfaatan Cloud Computing Bagi Usaha Kecil Menengah (UKM). Prosiding Seminar Nasional Geotik, 1-9. https://publikasiilmiah.ums.ac.id/bitstream/handle/11617/9072/geotik2017_1 .pdf?isAllowed $=\mathrm{y} \&$ sequence $=1$

Suryati, S., Disurya, R., Ermini, E., Sardana, L., Husnulwati, S., Wahyuningsih, S., 
\& Jumroh, J. (2019). Sosialisasi Praktik dan Perlindungan Pengguna Internet di SMA Negeri 1 Sungai Liat. Jurnal PkM Pengabdian Kepada Masyarakat, 2(02), 167. https://doi.org/10.30998/jurnalpkm.v2i02.3466

Zahara, S., Sugianto, \& M. Bahril Ilmiddafiq. (2019). Prediksi Indeks Harga Konsumen Menggunakan Metode Long Short Term Memory (LSTM) Berbasis Cloud Computing. Jurnal RESTI (Rekayasa Sistem Dan Teknologi Informasi), 3(3), 357-363. https://doi.org/10.29207/resti.v3i3.1086 